\title{
Os "mazelas" e os "dormentes": estratégias de resistência de jovens trabalhadores do call center
}

\section{The "mazelas" and the "dormentes": the resistance strategy of call center's young workers}

\section{Márcio Renato Teixeira Benevides ${ }^{1}$}

\section{Resumo}

Este artigo é fruto de uma pesquisa com jovens ex-funcionários de uma empresa de call center de Fortaleza e discute formas de resistência em uma empresa onde os funcionários permanecem em média um ano e meio e que os índices de insatisfação são enormes. Os teleoperadores estão segmentados em dois grupos, cujos nomes são nativos. Os "mazelas", conhecidos por sabotar os procedimentos da empresa, não realizando o exigido pela supervisão e nem cumprindo com as metas e resultados impostos e os "dormentes", que atuam numa resistência passiva ao ficar empregado por mais tempo que o

${ }^{1}$ Bacharel em Ciências Sociais pela Universidade Federal do Ceará. Mestre em Sociologia pelo Programa de PósGraduação em Sociologia da Universidade Federal do Ceará. Atualmente, Doutorando em Sociologia pelo Programa de Pós-Graduação em Sociologia da Universidade Federal do Ceará e Professor Substituto do Departamento de Ciências Sociais da Universidade Regional do Cariri.

Email:marcio_rhcp@yahoo.com.br.

Revista Cadernos de Estudos Sociais e Políticos, v. 5, n. 9, jan-junho 2016 
habitual e até desempenhando bem o trabalho. Travo discussões a partir de suas narrativas e experiências, problematizando as multiplicidades.

Palavras-chave: trabalho, call center, resistência.

\begin{abstract}
This article is the result of a research into young former employees of a call center company from Fortaleza and work on ways of resistance in a company where employees job tenure averages 1.5 year and dissatisfaction indexes are high. Teleoperators are segmented in two groups, whose names are native. The "mazelas" are known for sabotaging company's procedures, neither doing what they are requested by supervision nor fulfilling goals and results imposed and the "dormentes", act in a passive resistance staying employed longer than usual and even well doing the job. I discuss from their narratives and experiences, problematizing the multiplicities.
\end{abstract}

Keywords: work, call center, resistance.

Revista Cadernos de Estudos Sociais e Políticos, v. 5, n. 9, jan-junho 2016 


\section{O locus e os interlocutores}

A pesquisa apresenta o universo de uma empresa de call center, intitulada ficticiamente de X Center ${ }^{2}$, que há pouco mais de 10 anos possui uma filial na cidade de Fortaleza, contando com quase 10 mil funcionários. Desde 2010, realizei entrevistas e conversações com quase 100 interlocutores, entre funcionários e ex-funcionários. A empresa é organizada em setores, mas dialoguei especificamente com funcionários do teleatendimento receptivo (uma espécie de "porta de entradas" para os clientes para suas demandas).

Este artigo é um dos resultados de uma breve trajetória de pesquisa, que se iniciou com a busca pela compreensão dos motivos para a adesão ao trabalho no call center e como se dava o processo de desligamento dos funcionários por conta da descartabilidade funcional ${ }^{3}$. Também discuti como vários funcionários utilizavam-se do trabalho como um trampolim, proporcionando o financiamento dos estudos em faculdades privadas ou buscando promoções para outros cargos, sinalizando a circunstancialidade e a insatisfação com a atual posição.

O perfil dos funcionários da empresa é predominantemente composto por jovens, oriundos de escolas públicas, moradores das periferias da Região Metropolitana de Fortaleza e com renda mensal familiar de até três salários

\footnotetext{
${ }^{2}$ Neste trabalho foi utilizado o nome fictício de "X Center" para a empresa pesquisada. Metodologicamente, optei por não identificá-la para esclarecer que não se trata de uma situação peculiar, mas que se liga a uma série de organizações que executam suas relações de trabalho de um mesmo modo no cenário internacional das formas de trabalho no capitalismo contemporâneo.

${ }^{3}$ Um ano e meio é o tempo médio de duração de um funcionário do call center, demonstrando a alta rotatividade do serviço.
} 
mínimos. Deste universo, selecionei jovens funcionários e ex-funcionários com quem dialoguei para a produção específica deste artigo.

\section{A empresa domina, mas não totaliza}

O cenário do mundo do trabalho flexível é pesado e os estratagemas de cobrança e pressão sobre os funcionários se dão com o "permissionismo" das leis trabalhistas, que ampliam o poder das empresas. É um aglomerado de setores em busca da extração máxima de trabalho nas piores condições possíveis, garantindo baixos custos.

A empresa pesquisada faz os trabalhadores assumirem ritmos exaustivos em busca de metas diárias. Os indicativos da contratante estão ligados a pressupostos implícitos (como o "valor" do trabalho e a "oportunidade" de crescimento) e a uma obrigação social de ascender socialmente. Deleuze e Guattari (1995) afirmam que "os agenciamentos coletivos criam as palavras de ordem". A disciplina e as regras da empresa moldam seus trabalhadores, como em Foucault (2002).

Todavia, esse poder e seus "agenciamentos maquínicos de corpos" não são totalizantes, uma vez que não afetam os agentes da mesma forma (Deleuze e Guattari, 1995). Foucault (1988) diz que o poder é onipresente, não por englobar tudo, mas por brotar nos entroncamentos possíveis para seu nascimento. Uma prova de atuação em contrapartida a esse poder lógico está nos dois grupos resistentes aqui discutidos. Bourdieu (1988) destaca que o poder não é substância, nem é coisificado, pois não é algo que possa sequer ser detido.

Revista Cadernos de Estudos Sociais e Políticos, v. 5, n. 9, jan-junho 2016 


\section{Os "mazelas"}

Os "mazelas" são característicos pelo boicote às regras e metas, além de destratar ou sequer atender aos clientes. Além disso, faltam ao trabalho de maneira que "prejudique" a empresa, justificando as ausências por meio de atestados médicos (verdadeiros e falsos). Esse tipo de falta é tido como negativo, comprometendo o planejamento da empresa. A prática do absenteísmo proposital e justificado obriga a remuneração do dia em que o funcionário não trabalhou.

A seguir, temos alguns exemplos de narrativas que contam essas práticas. No primeiro, há um relato de um teleoperador que se explica a partir das metas. No segundo caso, há uma colocação sobre a utilização de atestados médicos. Por fim, temos um exemplo que se aponta como mais ofensivo e voltado para uma crítica à supervisão.

As metas da empresa não existem. Eles querem cobrar algo da gente que é impossível de se bater. Não tem como bater as metas como eles pedem sem se machucar. O que eu vou fazer? Vou ficar louco? Ficar louco pra não ganhar um centavo a mais? Eu precisava muito do trampo e por isso fiquei lá esse tempo todinho, mas, meu amigo, não tem a menor condição de você se matar por um salário mínimo e no final das contas não receber nem um centavo a mais e nem um obrigadozinho pra bater o ponto. A empresa parece que deseja é fabricar gente doida. (Exteleoperador, 26 anos)

Eu precisava sair de lá e eu ia fazer qualquer coisa pra conseguir 
isso. Tinha me tocado que ficar indo trabalhar, mesmo sem fazer absolutamente nada não ia resolver minha situação. Pedi as contas várias vezes e eles não me deram. Teve supervisor lá que me recomendou várias e várias vezes que eu pedisse minha demissão, mas e aí? Vou sair com o rabo entre as pernas e não levar nada? Passei dois anos me dedicando àquele negócio e sair de lá liso? Fala sério. Aí comecei a mazelar pesado e colocar atestado. Não me sinto um monstro por isso não. Ao contrário, foi só assim que deu certo. Depois de colocar uns cinco atestados, fui demitido e recebi os meus direitos. Lá, só vai se for assim. (Ex-teleoperador, 25 anos)

Os supervisores se fazem de doidos. Não conseguem ver a situação do operador. A maior marmota da empresa é isso! Os caras saem do atendimento e fingem que nunca atenderam um telefone. Tudo era mazela também, aí depois quer pagar de bichão com a gente e cobrar coisas que duvido terem feito também. Meus supervisores nunca me respeitaram como gente e eu também não fazia o que eles pediam. Tem uma hora que enche o saco e tudo o que você realmente deseja é ser demitido e sair de lá o quanto antes. (Ex-teleoperadora, 27 anos)

Há uma relação entre a prática da "mazela" e a necessidade de sair da empresa sem pedir demissão. Portanto, é uma resposta resistente a um aprisionamento do trabalhador, que age em busca do recebimento dos seus direitos trabalhistas. Uma relação de dependência, que estimula rancores e ações diretas, desestabilizando as normas do call center e produzindo subversão.

Estratégias de resistência como essas promovidas pelos "mazelas" foram 
encontradas em outros call centers, como em Rosenfield (2009). No trecho a seguir, a autora demonstra algumas estratégias de resistência, investidas por meio das ações dos "mazelas"

Diante da vivência de um trabalho com alto controle, os operadores desenvolvem formas de resistência a ele, enquanto forma de exercício de uma autonomia real. Alguns exemplos: para aliviar a pressão, alguns operadores fazem atividades paralelas desvinculadas da tarefa [...]; descobrem mecanismos que possibilitem voltar para o fim da fila dos atendentes que aguardam chamadas dos clientes; omitem informações ao cliente que possam comprometer a venda; desligam (dito "derrubar") para diminuir o tempo médio da chamada ou para abandonar um cliente complicado ou um serviço que não reverte em comissão; fazem uma pausa para procurar informações sem fazê-lo realmente (Rosenfield, 2009, p. 180).

Há os tipos de "mazela" que não estão focados em atacar a contratante, mas funcionam como uma defesa do trabalhador. Muitos "mazelas" atuam para diminuir os efeitos das cobranças da empresa. "Desopilar" é uma palavra comum nos relatos, pois mazelar pode ser uma fuga da pressão e uma maneira de preservar-se fisicamente e psicologicamente. A seguir, um trecho de uma ex-teleoperadora de 26 anos:

Eu só não queria chegar em casa chorando e morta de cansada por conta de cliente nenhum. Queria dormir sem ficar escutando o barulho do telefone. Queria ir pra aula no outro dia de manhã sem ter a impressão de que passei a noite carregando cimento nas costas. Eu mazelava porque não queria me estressar e nem ficar doida. Menino, é cada cliente que aparece e que lhe trata como se 
você fosse um lixo. Daí, quando dava, eu segurava a ligação de um cliente tranquilo por horas $\mathrm{e}$ horas e derrubava os estressadinhos na primeira grosseria. Eu acho que estava certíssima. Sério mesmo. Besta é quem acha que vale a pena se matar por uma coisa louca daquelas.

O conhecimento técnico sobre procedimentos e "macetes" do ofício torna o “mazela" perigoso para a empresa. É a utilização do saber como ferramenta de subversão ${ }^{4}$. Essa não é uma característica que brotou no call center. Desde o capitalismo industrial na Inglaterra do século XVIII já havia sabotagem contra os patrões, por meio da "tradição anônima" e dos "atos obscuros", como a destruição das máquinas (Thompson, 1998).

Na pesquisa realizada em montadoras de automóveis, em Bernardo (2009), vê-se subversões da linha da "mazela". Essas ações eram antidisciplinares e serviam como prática coletiva, uma vez que um grupo de agentes executava ações contrárias aos protocolos, deslocando o papel questionador que caberia aos sindicatos para eles próprios.

Os "mazelas" entrevistados assumem parcialmente a responsabilidade sobre suas ações, mas negam seu caráter ruim, caracterizando o que Austin (1979) chama de justificativa, demonstrando anseios sobre liberdade e responsabilidade. Esse raciocínio é ilustrado na fala a seguir:

Assim... Supervisor fica puto e diz que estou prejudicando o trabalho de todo mundo. E eu sei que tô errado, que tô fazendo o

\footnotetext{
4 A competência para se executar as práticas dos "mazelas" passa também pela instrumentalização dos conhecimentos sobre os próprios procedimentos da empresa. A contrautilização desses sistemas técnicos também é discutida por Zarifian (1996).
} 
trabalho de outro jeito. O negócio é que isso não é ruim pra empresa, porque ela já tem muita gente fazendo o que ela manda. Eu só quero conseguir sair daqui. (Teleoperador, 22 anos)

Essa declaração vai ao encontro do que Scott e Lymann (2009) definiram como accounts. A justificativa tenta preencher parte da lacuna entre as ações e as expectativas destes agentes. Em ações nocivas isso se destaca. O depoimento supracitado entraria na categoria denial of the victim, onde há uma afirmação de que o objeto da lesão (a empresa e suas regras) mereceu o ato (a "mazela"). Mais um trecho segue para se pensar na mesma linha:

Você fazer o certo aqui não vale de nada. Nunca vi ninguém chegar em canto nenhum obedecendo tudo o que eles pedem. Até porque num tem cristão no mundo que consiga. Todo mundo que eu conheci e inventou de fazer o que a empresa quer, acabou foi ficando doente ou pediu demissão na primeira chance que teve. Comigo acabou sendo assim... consegui outro emprego e pedi pra sair. Não precisava ficar num canto onde só se valoriza o que é errado. Mentir, enganar, passar por cima dos outros... esses são os grandes valores da X Center [alteração minha]. (Ex-teleoperador, 29 anos)

O conhecimento sobre as "mazelas" é repassado pelos veteranos como uma série de técnicas e de atos rebeldes que se propagam em forma de práticas de saber e de poder. Há uma referência de ensinamento quando se fala sobre as primeiras mazelas:

Eu mesmo comecei porque já não estava mais aguentando e via os veteranos fazendo e ficando mais relaxados. Aí você vai se chegando e acaba aprendendo algumas coisas. A gente já sabe 
mexer no sistema e acaba percebendo que ele não é perfeito. Aí quando vem a vontade de fazer errado e ninguém quer ser besta, aí dá certinho... (Ex-teleoperador, 26 anos)

Rapaz, umas amigas minhas que já tinham trabalhado lá viviam dizendo que tinha muita coisa errada que dava pra fazer, mas eu procurava me afastar e nem saber o que era, né? Lembro que no primeiro dia de trabalho já teve operador que quis me ensinar a mazelar, mas eu queria mesmo era fazer meu trabalho direito. Depois, quando você pega abuso, aí é facinho descobrir como se faz e aí a gente bota é pra lascar mesmo (risos). Você vai bem ficar sendo besta, hein? (Ex-teleoperadora, 22 anos)

A apresentação dos motivos, por meio da explicação de lesar a empresa, é forte e agrega adeptos à prática. Segundo Mills (1940), essa apresentação de motivos não é meramente descritiva, mas influencia uma adesão cotidiana, a partir da verbalização. Outra teleoperadora comenta sobre suas "mazelas":

A gente mazela aqui não é nem pra sacanear não, sabe? O negócio é que aqui só vai pra frente quem é malandro. $\mathrm{O}$ cara se matar de trabalhar não tem futuro. Vê aí os supervisores? Tudo já mazelaram! Um aí que até foi da minha bateria ${ }^{5}$, mazelava, mazelava, mazelava e nunca deu bucho. Então, vou pegar leve também por aqui, né? (Teleoperadora, 24 anos)

Essa última declaração encontra-se disposta com a justificativa condemnation of the condemners (Scott e Lymann, 2009, p. 51). Nesse modelo, o agente reconhece a ação efetuada, mas salvaguarda-se em argumentos que afirmam

\footnotetext{
5 "Bateria" é o conjunto de 20 teleoperadores sob o controle de um supervisor. Essa é a terminologia utilizada no organograma da empresa analisada.
}

Revista Cadernos de Estudos Sociais e Políticos, v. 5, n. 9, jan-junho 2016 
que outros já o fizeram e nunca foram punidos, nem flagrados e que até lograram êxito.

A condição precária de trabalho é justificativa para vários operadores "mazelas". Um dos interlocutores diz que seus atos são respostas à sobrecarga física e psicológica que o call center promove. A visão dele é de que "mazelar" é uma defesa:

A questão da mazela no trabalho, ela não é nada mais, nada menos do que um mero efeito na relação de exploração e tal. Se você procura mazelar no trabalho é, na minha visão, [...] sobrecarga de trabalho. Você tava muito estressado e você procurava outras formas de poder amenizar o seu expediente no dia-a-dia lá no trabalho e tal. Por isso que eu penso assim, eu acho que é basicamente isso. (ex-teleoperador, 22 anos)

Outra explicação para os atos de "mazela" mora no revide à ideologia do trabalho excessivo e supercontrolado do call center. Um dos "mazelas" utilizou "ideologia" como algo negativo. Para ele, as "mazelas" são "fraudes necessárias para se trabalhar". O jovem disse ainda que "nenhum dos valores exigidos pela empresa são cumpridos". Em sua consciência explicativa, "mazelar" beira a sinceridade ao refutar os códigos pregados, sobretudo na relação com os clientes, envolvendo ações de ludibriar.

A subversão dá-se por prazer ou para escapar das redes de controle e dominação? $\mathrm{O}$ fato é que há táticas de combate ao que é imposto aos teleoperadores, inclusive como práticas coletivas, tendo em vista que há aprendizado, aos moldes do que se discute em Certeau (1996).

\section{Os "dormentes"}

Revista Cadernos de Estudos Sociais e Políticos, v. 5, n. 9, jan-junho 2016 
Os "dormentes" são assim chamados porque trabalham numa diferenciada robotização e internalização de procedimentos e regras. Esses teleoperadores o fazem sem a pretensão de galgar espaços na empresa ou de serem reconhecidos pelo que fazem. Inclusive, os interlocutores desse grupo dizem não gostar do trabalho.

Quando questionados sobre o que pensam da empresa, dizem que "tanto faz". São antissociais, não se relacionando com os colegas. É raro encontrar um “dormente" na empresa. Em diálogo com Sennett (2008, p. 170), observo que muitos absorveram os ideais do individualismo e são suficientemente vulneráveis para experienciar e permitir relações de dependência uns com os outros.

O ódio é elemento presente em algumas falas dos "dormentes", mesmo preservando princípios ligados a uma condição e postura ética de difícil assimilação:

Eu acho que esse é o pior emprego do mundo que uma pessoa pode ter. Todo mundo lá fora fala da X Center [alteração minha] como se fosse um negócio de escravos e eu sei que é horroroso mesmo, mas não tenho outra coisa pra fazer. Nunca fiz um curso de nada na vida e então eu tenho mais é que tentar pegar experiência aqui. Queria muito ter paciência que nem os outros, mas, na moral, só o fato de vir pra cá quase todo dia já é pra ser herói (risos discretos). Quero mesmo é um dia sair daqui com o currículo melhor e arrumar uma coisa que me faça feliz. (Teleoperador, 23 anos)

Rebusco uma abordagem semelhante à de Misse (2010), refletindo sobre 
grupos espoliados e subjetivados, mas sem esperar deles um caráter contrahegemônico. Existem outros tipos de assujeitamento, podendo ser cínicos, silenciosos e egoístas. O depoimento abaixo reflete essa condição:

Cara, eu nem sei o que sinto sobre isso aqui. Não sei o que acontece comigo. Não sei te explicar. Sinto que eu sou um trabalhador normal, só que não carrego sentimento nenhum. Não quero ficar aqui, mas também não quero sair daqui. Sei que nunca vou ser supervisor, porque não sou amiguinho de ninguém e acredito que poucos gostam de mim. Tenho uma filha pra criar e só consigo pensar nela. Acho um bom motivo. Agora, até quando eu vou fazer isso é que eu num sei. Sei lá... mas tenho que vir trabalhar todo dia, porque é isso que bota comida na minha mesa. [...] sou indiferente com a empresa, porque eu também acho que ela é comigo. Sou um trabalhador a mais e ela é uma empresa a mais. (Teleoperador, 25 anos)

O próprio silêncio possui significados que podem conter "sopros de liberdade crítica”, conforme Pollak (1989). Entretanto, nem todo resgate das memórias contidas nesse silêncio trará "memórias subterrâneas". Os "dormentes" trivializam as dificuldades cotidianas por possuírem prioridades individuais, como o sustento dos filhos ou o financiamento de uma faculdade.

Eu aqui entro muda e saio calada. Não aguento mais. Quando estou vindo no ônibus já sinto vontade de vomitar. Ver todo mundo se estrepando nesse serviço, incluindo eu mesma, é osso de aguentar. Botei na minha cabeça que não preciso fazer nada mais do que trabalhar e isso que eu estou fazendo. Chego, sento na P.A. e fico lá fazendo meu serviço quietinha e rezando pra acabar o serviço. Já chego querendo voltar pra casa e todo santo dia é a

Revista Cadernos de Estudos Sociais e Políticos, v. 5, n. 9, jan-junho 2016 
mesma coisa. O que eu sei é que um dia eu vou me formar e não precisar mais fazer um trabalho tão sem noção como o que eu faço. (Teleoperadora, 26 anos)

Em ambas as categorias, os motivos não devem ser encarados apenas como expressões desejantes, evitando o psicologismo, mas como importantes para interpretar as condutas. Os motivos, como em Mills (1940), são fenômenos sociais dispostos na realidade - do plano analítico - e prontos para uma explicação, que parte dos motivos iniciais, englobando motivos auxiliares que vão surgindo, as mudanças de perspectivas e todas as estratégias de ação contidas nesse processo.

Em minoria na teleoperação, os "dormentes" chamam a atenção pelo ritmo laboral constante, mesmo que em baixa intensidade, o que os torna um grupo de exceção em uma empresa com alta descartabilidade. Por não permitirem que o emocional se sobressaia, são incompreendidos pelos demais. Essa característica também dificultou o acesso da pesquisa, demandando um tempo maior no estabelecimento das relações.

\section{Outras reflexões e contribuições}

Há uma luta por representações na Sociologia do Trabalho que, numa dimensão clássica, define de modo cristalizado a exploração do trabalho sem, via de regra, mencionar as formas de resistência e subversão. Tento demonstrar formas de agência dos trabalhadores sem um necessário sentido político-revolucionário. 
Chartier (2002, p.17) argumenta que "as percepções do social não são de forma alguma discursos neutros", mas sim produtoras de estratégias e práticas, numa tentativa de submeter o fato à autoridade de um projeto ou argumento. Compreender essas disputas pelas definições do real é buscar os "pontos de afrontamento" dos fenômenos sociais estudados.

No bojo das mudanças no "mundo do trabalho", tem-se um aumento do discurso psicológico no meio empresarial, seja na perspectiva da motivação, seja na dimensão da pressão por resultados. Illouz (2011) aponta como essas estratégias são utilizadas inclusive para gerir e identificar problemas nas empresas. Para se administrar, é necessário fazer às vezes de psicólogo em uma grande corporação.

A escuta da raiva, da contestação, da insatisfação, das queixas dos trabalhadores é fundamental para o feedback empresarial. Uma das dificuldades desse mapeamento das empresas está na característica secreta das ações produzidas pelos "mazelas" e pelos “dormentes", numa produção semelhante à "tradição anônima" demonstrada por Thompson (1998).

Para Illouz (2011), esta psicologização também pode ser encarada como uma tentativa de neutralização da luta de classes. Entretanto, como apontado em outro momento, não é possível haver uma totalização da teleoperação e sempre haverá formas de reação a uma tentativa de substancialização dos trabalhadores.

Deste paradigma afetivo, pode-se pensar que a insegurança presente no atual modo de se produzir trabalho também promove sentimentos que ligam as pessoas. Portanto, se o afeto é utilizado como instrumento para aumentar a 
produtividade, as lutas afetivas também produzem afetos contraproducentes por meio da solidariedade. A autora diz:

O afeto não é uma ação em si, mas é a energia interna que nos impele a agir, que confere um "clima" ou uma "coloração" particulares a um ato. Por isso, o afeto pode ser definido como o lado da ação que é "carregado de energia", no qual se entende que essa energia implica, simultaneamente, cognição, afeto, avaliação, motivação e o corpo. [...] os afetos são significados culturais e relações sociais inseparavelmente comprimidos (p. 9).

No grupo dos "mazelas" há uma rede de solidariedade, inclusive no ensino das práticas. Pela característica clandestina dessas ações, a única maneira de se repassar o conhecimento e de proteger-se é na cooperação fomentada pelas interações. Nesse sentido, vê-se a prática como coletiva e solidária.

A formação de uma comunidade de "mazelas" parece com a formação de uma comunidade de trabalhadores em Hoggart (1973). Inclusive, a noção da necessidade de um "isolamento" promovendo a divisão entre o "nós" e o "eles" é fundamental, principalmente pela ideia de que não há acolhimento no mundo dos "patrões". A satirização dos funcionários que trabalham seguindo os procedimentos formais é semelhante.

Pensar nessas possibilidades de ação em uma mesma empresa é pensar nas formas cotidianas de se produzir o trabalho. Isso se aproxima do que Williams (1969) chama de "modos de vida". Como definiu Costa (2012), para se pensar práticas culturais não é possível encarar o mundo nem da perspectiva de uma "dominação unilateral", nem do âmbito de uma "recepção monolítica". Do mesmo modo opera o mundo do trabalho, onde há

Revista Cadernos de Estudos Sociais e Políticos, v. 5, n. 9, jan-junho 2016 
formas de reação e agência.

A própria definição de classe social não pode ser talhada de modo cristalizado e desconexo da historicidade. Thompson (1987, p. 12) diz que "a classe é definida pelos homens enquanto vivem sua própria história e, ao final, esta é sua única definição". Para ele, classe não é estrutura, mas categoria. Pensar classes sociais em Thompson abre uma janela de estudos sobre movimentos contra hegemônicos, com a mesma relevância dos estudos de movimentos hegemônicos (Costa, 2012, p. 165) ${ }^{6}$.

Hoggart (1973) mostra como, a partir de sua experiência, sem perseguir uma pretensa verdade científica, é possível construir outra imagem do que se entende por "povo" e por "trabalhador". O autor faz uma crítica as leituras românticas sobre as classes trabalhadoras, que não compreendem as mudanças que ocorrem no mundo do trabalho, achando que a tradicional classe proletária está enfraquecendo.

Para Hoggart, isto se trata de uma "frustração", bem como a projeção de uma noção de engajamento atribuída por uma literatura de estudos clássicos, agindo ora com piedade e ora com supradimensionamento do potencial dos trabalhadores. Lanço a questão: como essa reflexão tradicional encararia as práticas dos "mazelas" e dos “dormentes"?

Certamente haveria uma tentativa de enquadrá-las num espírito revolucionário ou atribuiria à dimensão individualista e de fuga da consciência de classe. Hoggart diz que a Sociologia precisa compreender a multiplicidade e o que os "dados" significam para a própria classe

\footnotetext{
${ }^{6}$ Ver mais sobre isso em Mattelart e Neveu (2004) e Cevasco (2003).
}

Revista Cadernos de Estudos Sociais e Políticos, v. 5, n. 9, jan-junho 2016 
trabalhadora. Ou seja, compreender como “os hábitos representam para além dos hábitos”, evitando generalizações de toda espécie.

É lícito procedermos a generalizações no que se refere às atitudes características do proletariado, o que não implica que todos os indivíduos dessas classes pensem ou procedam dessa maneira em relação ao trabalho, ao casamento ou à religião. [...] As generalizações a que procedo ao longo deste livro significam apenas que a maioria das pessoas do proletariado consideram que assim se deve pensar ou agir neste ou naquele caso (Hoggart, 1973, p. 27).

Ter noção das diferenças de práticas entre os trabalhadores de uma mesma empresa é evidenciar que os processos de formação social e de assujeitamento se dão em dimensões diversas, fugindo da crise teórica visualizada por Canclini (2003, p. 2007). Como definiu Costa (2012, p. 160), as lutas dos trabalhadores não são necessariamente as lutas "para além do Capital", como apontou Mészáros (2008), podendo se expressar pelas lutas cotidianas e "pela vida de todo o dia".

\section{Considerações finais}

Não posso afirmar se há algum caráter emancipatório nos grupos discutidos, tampouco afirmar se há uma necessária intencionalidade direta em suas ações. O fato é que tanto os "mazelas" como os "dormentes" atuam em resistência. A primeira categoria atua numa frente de maior acidez, ao entrar em enfrentamento direto com a empresa. $\mathrm{O}$ outro grupo se molda ao jeito de 
trabalhar que a empresa impõe, almejando outros resultados objetivos a partir do seu trabalho e sem entrar na pressão colocada pela rotina scriptizada, apesar de cumprir com essa demanda.

Tenho em vista que, como afirmou Barthes (2001), "a melhor arma contra o mito é mitificá-lo a ele próprio". Logo, fazer o "roubo" desse mito de que o trabalhador do call center é apenas uma vítima, assujeitado e explorado, é uma forma de criar uma nova mitologia, destacando, desta vez, as experiências de resistência nas trajetórias dos agentes com quem vivi a ação da pesquisa.

Este artigo não pretende ser necessariamente outra tradução da realidade do call center e, assim como não trouxe respostas definitivas, não diagnostica uma concretude do "real". Não analiso outra realidade, mas - sendo atravessado por Deleuze e Guattari (1995) - reflito sobre outros modos de agenciamentos, de práticas, de discursos e de relações.

Desenvolvo uma cartografia das relações destes agentes e de suas maneiras de lidar com as tarefas cotidianas. Mesmo criando representações, destaco que a análise científica não é hierarquicamente superior ou inferior às análises produzidas pelos agentes pesquisados (Schutz, 1943). Isto também não significa que minha missão tenha sido apenas a de transformar a voz destes em teoria final $^{7}$.

A tentativa da diminuição do poder coercitivo da análise torna-se uma de minhas missões enquanto pesquisador. Transformar a pesquisa não apenas numa ação profissional de coleta de informações e de extração dos dados a

${ }^{7}$ Ver mais sobre essa questão em Garfinkel (1967).

Revista Cadernos de Estudos Sociais e Políticos, v. 5, n. 9, jan-junho 2016 
partir do deslocamento dos agentes de suas agências, mas numa forma de sociabilidade recíproca entre pesquisador e pesquisados.

Revista Cadernos de Estudos Sociais e Políticos, v. 5, n. 9, jan-junho 2016 


\section{Referências Bibliográficas}

AUSTIN, John L. “A plea for excuses”. In: Philosophical papers. Londres, Oxford University Press, 1979 [1956].

BARTHES, Roland. Mitologias. Rio de Janeiro: Bertrand Brasil, 2001.

BERNARDO, Marcia Hespanhol. Trabalho duro, discurso flexivel: uma análise das contradições do toyotismo a partir da vivência de trabalhadores. São Paulo: Expressão Popular, 2009.

BOURDIEU, Pierre. Lições de aula: aula inaugural proferida no Collège de France. São Paulo: Ática, 1988.

CANCLINI, Néstor Garcia. Culturas híbridas: estratégias para entrar e sair da modernidade. São Paulo: Edusp, 2003.

CERTEAU, Michel de. A invenção do cotidiano: artes do fazer. Petrópolis: Vozes, 1996.

CEVASCO, Maria Elisa. Dez lições sobre Estudos Culturais. São Paulo: Boitempo, 2003.CHARTIER, Roger. A história cultural entre práticas e representações. Algés, Portugal: Difel, 2002.

COSTA, Jean Henrique. "Os estudos culturais em debate: um convite às obras de Richard Hoggart, Raymond Williams \& E. P. Thompson". Acta Scientiarum, Human and Social Sciences, vol. 34, n 2, 2012, pp. 159-168.

DELEUZE, Gilles; GUATTARI, Félix. "20 de Novembro de 1923 postulados da linguística". In: Mil platôs: capitalismo e esquizofrenia, vol. 2. São Paulo: 34, 1995.

FOUCAULT, Michel. A história da sexualidade I: a vontade de saber. Rio de Janeiro: Graal, 1988.

Vozes, 2002.

. Vigiar e punir: história da violência nas prisões. Petrópolis:

GARFINKEL, Harold. "Studies in routine grounds of everyday activities". In: Studies in ethnometodology. Cambridge, Prentice-Hall, 1967.

Revista Cadernos de Estudos Sociais e Políticos, v. 5, n. 9, jan-junho 2016 
HOGGART, Richard. As utilizações da cultura: aspectos da vida da classe trabalhadora com especiais referências a publicações e divertimentos.

Lisboa: Presença, 1973.

ILLOUZ, Eva. O amor nos tempos de capitalismo. Rio de Janeiro: Zahar, 2011.

MATTELART, Armand; NEVEU, Érik. Introdução aos estudos culturais. São Paulo: Parábola Editorial, 2004.

MÉSZÁROS, István. A educação para além do capital. São Paulo: Boitempo, 2008.

MILLS, C. Wright. "Situated actions and vocabularies of motive". American Sociological Review, vol. 5, n 6, 1940, pp. 904-913.

MISSE, Michel. "Crime, sujeito e sujeição criminal: aspectos de uma contribuição analítica sobre a categoria 'bandido"'. Lua Nova, no 79, 2010, pp. 15-38.

POLLAK, Michael. "Memória, esquecimento, silêncio". Estudos Históricos, vol. 2, no 3, 1989, pp. 3-15.

ROSENFIELD, Cinara Lerrer. "A identidade no trabalho em call centers: a identidade provisória”. In: ANTUNES, Ricardo; BRAGA, Ruy (orgs.). Infoproletários: degradação real do trabalho virtual. São Paulo: Boitempo, 2009.

SCHUTZ, Alfred. "The problem of rationality in the social world". Economica, New Series, vol. 10, nº 38, 1943, pp. 130-149.

SCOTT, Marvin B.; LYMANN, Stanford. “Accounts [1968]”. Dilemas: Revista de Estudos de Conflito e Controle Social, vol. 2, no 2, 2009, pp. 139172.

SENNET, Richard. A corrosão do caráter: consequências pessoais do trabalho no novo capitalismo. Rio de Janeiro: Record, 2008.

THOMPSON, Edward Palmer. Costumes em comum. São Paulo: Companhia das Letras, 1998. . A formação da classe operária inglesa. Rio de Janeiro: Paz e

Revista Cadernos de Estudos Sociais e Políticos, v. 5, n. 9, jan-junho 2016 
Terra, 1987.

ZARIFIAN, Philippe. "A gestão da e pela competência". Trabalho apresentado no Seminário Internacional "Educação profissional, trabalho e competência", Centro Internacional para Educação, Trabalho e Transferência de Tecnologia, Rio de Janeiro, 1996.

WILLIAMS, Raymond. Cultura e sociedade (1780-1950). Tradução de Leônidas H. B. Hegenberg; Octanny Silveira da Mota e Anísio Teixeira. São Paulo: Companhia Editora Nacional, 1969.

Recebido em: 31/01/2015

Aprovado em: 03/02/2016 